\title{
ANO-GENITAL DISTANCE IN HEALTHY NIGERIAN FULL-TERM
}

\section{NEWBORN INFANTS}

\section{Onyiriuka AN 1 , Elusiyan JBE ${ }^{2}$}

${ }^{1}$ Endocrine, Metabolic and Genetic Unit, Department of Child Health, University of Benin Teaching Hospital, PMB 1111, Benin City, Nigeria, ${ }^{2}$ Endocrine and Metabolic Unit, Department of Paediatrics and Child Health, Obafemi Awolowo University Teaching Hospital, Ile Ife, Nigeria.

\section{ABSTRACT}

Background/Aim: In humans, anogenital distance (AGD) appears to provide a reliable guide to androgen exposure during fetal life. The aim of the present study is to determine the normal values for AGD in Nigerian newborns of both genders and to determine its association with birth weight and length.

Methods: For this descriptive cross-sectional study, 895 (448 males and 447 females) healthy full-term (37 to 42 weeks' gestation) infants between the age of 6 to 72 hours delivered in two Nigerian hospitals were recruited for this evaluation. A standardized anthropometric protocol was used to measure AGD, ano-scrotal distance (ASD) and ano-fourchette distance (AFD). The birth weight and the length of all the subjects were also measured and recorded.

Results: There was a total of 895 (448 males and 447 females) subjects for the study. The mean birth weights were $3288 \pm 472 \mathrm{~g}$ $(95 \% \mathrm{CI}=3244-3332)$ and $3125 \pm 552 \mathrm{~g}(95 \% \mathrm{CI}=3074-3176)$ for male and female infants, respectively; $\mathrm{p}<0.01$. The mean AGDs $( \pm S D)$ at birth were $28.3 \pm 3.9 \mathrm{~mm}(95 \% \mathrm{CI}=27.9-28.7)$ in males and $15.2 \pm 2.4 \mathrm{~mm}(95 \% \mathrm{CI}=15.0-15.4)$ in females; $\mathrm{p}<$ 0.001. The ratio of the male-to-female ano-genital distance (ASD/AFD) was 1.7. The adjusted AGD [AGD ASD / birth weight $(\mathrm{mm} / \mathrm{kg})]$ and $\left[\mathrm{AGD}_{\mathrm{AFD}} / \mathrm{birth}\right.$ weight $\left.(\mathrm{mm} / \mathrm{kg})\right]$ was 8.7 and 4.9 for male and female newborn infants, respectively.

Conclusion: The results of this study provide reliable normative values that can be used as a standard with regard to AGD in Nigerian male and female newborns at birth.

Keywords: Ano-genital distance, newborn, Nigerian

\section{INTRODUCTION}

Measuring anogenital distance (AGD) in newborns has been suggested as a noninvasive method of determining male feminisation and female masculinization that could be utilized to predict neonatal and adult reproductive disorders (1). AGD is an easy-to-measure, reliable and a sensitive marker of the effects of fetal androgens and the related endocrine-disrupting chemicals (EDCs) (2). The development of both the perineum and the external genitalia are determined by dihydrotestosterone and as a result, males have a longer AGD compared to females (3). Numerous animal studies have demonstrated that AGD is a sensitive indicator of prenatal androgen exposure and can be used as a means of retrospective measurement of fetal androgen exposure during the window of programming and masculinization of the reproductive tract $(3,4)$. In humans, AGD tracks from birth to early childhood and therefore, measurements at birth may be linked to later reproductive disorder $(5,6)$. In a report from the international panel of experts suggests that AGD is an important clinical measure to address endocrine-sensitive endpoints in the first year of life and recommended more in-depth examination of the measurement in humans (7). The availability of normative data provides a means of utilizing this biological marker of androgen action in population studies of the effect of environmental chemicals on genital development (6). Measurement of AGD may enable us to distinguish newborns with androgen deprivation from those with other causes, but this could only be done convincingly by comparison with normative values (8). Similar considerations may apply to adult men with gonadal problems and when trying to discern for example, whether a low sperm count had its origins in fetal life or not (8). In contrast, a longer AGD has been demonstrated in females with 
congenital adrenal hyperplasia (9) and multi-follicular ovaries (10). All these, reflect the usefulness of AGD measurements in both males and females.

Although AGD measurements sound straightforward, determining the actual measurement that needs to be taken and taking accurate measurements are 2 difficult tasks (10). Maintaining a newborn in the measurement position without moving, while the measurements are made, is difficult (10). In order to overcome this problem, several anthropometric protocols have been developed for the measurement of AGD. Romano-Riquer et al (11) have developed an anthropometric protocol for the measurement of AGD in human males. Similarly, SalazarMartinez et al (12), have developed an anthropometric protocol for both male and female newborns. They measured the distance from the centre of the anus to the junction of the smooth perineal skin with the rugated skin of the scrotum in male new-borns and the centre of the anus to the posterior convergence of the fourchette in female infants. There were two previous studies done in Nigeria using the same measurements. However, these did not adequately describe the steps taken to minimize measurement errors (13, 14).

AGD is morphologically a small distance and the reliability of anogenital measurement (AGM) is heavily influenced by measurement errors. The apparatus used for the measurements, the number of measurement taken, the experience of the person taking the measurements, availability of an assistant during the measurement and the number of investigators involved are some of the important factors that could influence the measurements (15). Although there were 2 studies done on AGD, smaller sample size and the coverage of a small geographical area of the country were major limitations of these studies $(13,14)$. The above considerations prompted the present study involving western and mid- western regions of Nigeria. The purpose of the present study is to determine the normal values for AGD in Nigerian newborns of both genders and to determine its association with birth weight, length and occipito-frontal circumference.

\section{METHODS}

\section{Study area}

The study was conducted in two hospitals in Benin City, namely, the University of Benin Teaching Hospital (UBTH), a tertiary healthcare level institution and in $\mathrm{St}$ Philomena Catholic Hospital (SPCH), a secondary healthcare level institution. SPCH is located at the center of Benin City and is the second largest maternity unit in Benin City. In both hospitals, as a policy, the mothers usually kept for 2-3 days postpartum before discharge. This ensured the availability of the newborn infants for physical examination including AGD measurements during the first 72 hours of life. The study was conducted over a period of 4 months from October 2013 to January 2014. The study was conducted after obtaining ethical approval from the Ethics and Research Committee of the University of Benin Teaching Hospital. Permission was obtained from the authorities of the two hospitals. After informing the specific objectives of the study, written informed consent was obtained from the mothers for the study. A questionnaire was used in obtaining data from the mothers, regarding the obstetric history such as maternal age and parity.

\section{Study population}

Eight hundred and ninety-five (895) consecutively delivered healthy fullterm (37 to 42 weeks of gestation) newborn infants aged between 6 and 72 hours whose parents gave consent for the newborn physical examination and AGD measurement were recurited for the study. The stillborn, premature babies and babies born with congenital illness or congenital anomalies of the external genitalia or imperforate anus were excluded from the study.

\section{Anthropometric measurements}

A female nurse was trained in the method of holding and positioning the newborn infant for examination of the external genitalia and measurement of AGD. She also acted as a chaperone during the newborn physical examination. In order to minimize ano-genital measurement errors, we measured ano-scrotal distance in males and ano-fourchette distance in females, which are the easily identifiable soft tissue landmarks, as suggested by Thankamony et al (6). The AGD was measured with the newborn infant placed in the dorsal decubitus position on a table. The assistant stood at the infant's head end and held the infant's thighs in a flexed position with her hands, while placing her forearm on the baby's arm to minimize movement of the newborn (9). The anthropometrist positioned himself in front of the baby and using a flexible inelastic tape, Ano-scrotal distance (ASD) was measured from the centre of the anus to the junction of the smooth perineal skin with the rugated skin of the scrotum in male newborns (9). In female infants, Anofourchette distance (AFD) was measured from the centre of the anus to the posterior convergence of the fourchette, where the vestibule begins (11). All the measurements were recorded in millimetres. To minimize measurement errors, three consecutive measurements were taken at each assessment and the average was recorded as the final value. In addition, all measurements were performed by a single examiner where the proficiency was validated before the beginning of the study.

The adjusted ano-genital distance was computed as follows:

$\mathrm{AGD}_{\mathrm{ASD}} /$ birthweight $(\mathrm{mm} / \mathrm{kg})$ for male infants.

$\mathrm{AGD}_{\mathrm{AFD}} /$ birthweight $(\mathrm{mm} / \mathrm{kg})$ for female infants. 
Other anthropometric parameters such weight, length and occipitofrontal circumference were measured, using standardized techniques.

\section{Statistical analysis}

The statistical analysis was performed using the SPSS software package version 15.0 (SPSS, Inc. Chicago, IL, USA). Descriptive statistics such as means, standard deviations, confidence intervals were used, as appropriate, to describe the variables. Student's t-test was used to assess the significance of differences between means. A p-value less than 0.05 was considered statistically significant.

\section{RESULTS}

There was a total of 895 (448 males and 447 females) newborn infants and their gestational ages were ranging from 38 to 42 weeks. The mean maternal age and parity in this general obstetric population were $27.8 \pm 4.6$ years and $1.5 \pm 1.2$, respectively. The mean birth weight was $3193 \pm 512 \mathrm{~g}$. It was $3288 \pm 482 \mathrm{~g}$ for male infants and $3125 \pm 552 \mathrm{~g}$ for female infants. The mean birth weight was significantly higher in males than females; $\mathrm{p}<0.01$ (Table 1). The mean AGD ( \pm SD) at birth was $28.3 \pm 3.9 \mathrm{~mm}$ in males and $15.2 \pm 2.4 \mathrm{~mm}$ in females; $\mathrm{p}$-value $<0.001$ (Table 2). The ratio of maleto-female $\mathrm{AGD}_{\mathrm{ASD}} / \mathrm{AGD}_{\mathrm{AFD}}$ was 1.7. The AGD/Birth weight $(\mathrm{mm} / \mathrm{kg})$ in male and female infants was 8.7 and 4.9 , respectively (Table 3 ). The ratio of the $\mathrm{AGD}_{\mathrm{ASD}} / \mathrm{Birth}$ length and $\mathrm{AGD}_{\mathrm{AFD}} /$ Birth length were 0.58 for males and 0.32 for females, respectively. A comparison of mean anogenital distances according to the measuring apparatus used and country of study is depicted in Table 4.

\section{DISCUSSION}

The programming of the genital organs occurs during 8-14 weeks of gestation (16). Development of perineum and external genitalia is determined by the dihydrotestosterone and the animal studies have demonstrated that exposure of rodent fetuses to androgens during fetal masculinization programming window resulted in longer AGD $(16,17)$. This effect of dihydrotestosterone explains the development of a longer AGD in males compared to females $(2,14,15)$. Our study also demonstrated that AGD is significantly longer in male than female newborns.

\begin{tabular}{|c|c|c|c|}
\hline Parameter & $\begin{array}{l}\text { Male }(\mathrm{n}=448) \\
(95 \% \mathrm{CI} * *)\end{array}$ & $\begin{array}{l}\text { Female }(\mathrm{n}=447) \\
(95 \% \mathrm{CI})\end{array}$ & $\begin{array}{l}\text { t-statistic } \\
\text { (p-value) }\end{array}$ \\
\hline Mean birth weight(g) & $\begin{array}{l}3288 \pm 482 \\
(3243-3333)\end{array}$ & $\begin{array}{l}3125 \pm 552 \\
(3074-3176)\end{array}$ & $\begin{array}{l}4.705 \\
<0.01\end{array}$ \\
\hline Mean birth length $(\mathrm{cm})$ & $\begin{array}{l}49.4 \pm 0.9 \\
(49.3-49.5)\end{array}$ & $\begin{array}{l}47.7 \pm 0.7 \\
(47.6-47.8)\end{array}$ & $\begin{array}{l}31.545 \\
<0.001\end{array}$ \\
\hline Mean $\mathrm{OFC}^{*}(\mathrm{~cm})$ & $\begin{array}{l}34.4 \pm 0.6 \\
(34.3-34.5)\end{array}$ & $\begin{array}{l}34.2 \pm 0.7 \\
(34.1-34.3)\end{array}$ & $\begin{array}{l}0.998 \\
>0.05\end{array}$ \\
\hline
\end{tabular}

$* \mathrm{OFC}=$ Occipito-frontal circumference; $* * \mathrm{CI}=$ Confidence interval

\begin{tabular}{lc}
\hline $\begin{array}{l}\text { Table 3: Adjusted anogenital distance for birth weight, length and } \\
\text { occipito-frontal circumference according to gender }\end{array}$ \\
\hline Parameter & $\begin{array}{c}\text { Adjusted AGD } \\
\text { for body size }\end{array}$ \\
\hline $\mathrm{AGD}_{\mathrm{ASD} *} /$ Birthweight $(\mathrm{mm} / \mathrm{kg})$ males & 8.7 \\
$\mathrm{AGD}_{\mathrm{AFD} * *} /$ Birthweight $(\mathrm{mm} / \mathrm{kg})$ females & 4.9 \\
$\mathbf{A G D}_{\mathrm{ASD}} /$ Birth length $(\mathrm{mm} / \mathrm{cm})$ males & 0.58 \\
$\mathrm{AGD}_{\mathrm{AFD}} /$ Birth length $(\mathrm{mm} / \mathrm{cm})$ females & 0.32 \\
$\mathrm{AGD}_{\mathrm{ASD}} /$ Birth OFC $(\mathrm{mm} / \mathrm{cm})$ males & 0.82 \\
$\mathrm{AGD}_{\mathrm{AFD}} /$ Birth OFC $(\mathrm{mm} / \mathrm{cm})$ females & 0.44 \\
\hline
\end{tabular}

$* \mathrm{AGD}_{\mathrm{ASD}}=\mathrm{AGD}$-ano-scrotal distance; $* * \mathrm{AGD}_{\mathrm{AFD}}=$ AGD-ano-fourchette distance; $\mathrm{OFC}=$ Occipito-frontal circumference

Table 2: Comparison of ano-scrotal distance (male) and ano-fourchette distance (female) in newborn infants

\begin{tabular}{|c|c|c|c|c|}
\hline Parameter & $\begin{array}{c}\text { No of } \\
\text { infants }\end{array}$ & Mean \pm SD & $95 \% \mathrm{CI}$ & $\begin{array}{l}\text { t-statistic } \\
\text { (p-value) }\end{array}$ \\
\hline AGD: Ano-scrotal (mm) males & 448 & $28.3 \pm 3.9$ & $(27.9-28.7)$ & 60.531 \\
\hline AGD: Ano-fourchette (mm) females & 447 & $15.2 \pm 2.4$ & $(15.0-15.4)$ & $(<0.001)$ \\
\hline
\end{tabular}

$\mathrm{CI}=$ Confidence interval 
Table 4: Comparison of mean (SD) anogenital distance according to measuring apparatus used and country of study.

\begin{tabular}{lcccc}
\hline \hline Study & $\begin{array}{c}\text { Male AGD } \\
\text { ASD*(mm) }\end{array}$ & $\begin{array}{c}\text { Female AGD } \\
\text { AFD** (mm) }\end{array}$ & $\begin{array}{c}\text { Measuring } \\
\text { apparatus used }\end{array}$ & $\begin{array}{c}\text { Country } \\
\text { of study }\end{array}$ \\
\hline Thankamony et al [7] & $19.8 \pm 6.1$ & $9.1 \pm 3.8$ & Vernier caliper & UK \\
Sathyaranayana et al [16] & $23.0 \pm 3.8$ & $10.3 \pm 2.0$ & Vernier caliper & USA \\
Özkan et al [17] & $23.0 \pm 6.0$ & $10.3 \pm 2.0$ & Vernier caliper & Turkey \\
Papadopoulou et al [6] & $23.6 \pm 5.1$ & $13.8 \pm 2.5$ & Vernier caliper & Spain \\
Papadopoulou et al [6] & $27.1 \pm 4.4$ & $14.4 \pm 3.0$ & Vernier caliper & Greece \\
Oguz Kutlu [19] & $25.8 \pm 4.7$ & $13.4 \pm 3.2$ & Vernier caliper & Turkey \\
\hline Ovidime et al [15] & $31.1 \pm 6.4$ & $13.9 \pm 2.6$ & Flexible inelastic & Nigeria \\
Present study & $28.3 \pm 3.9$ & $15.2 \pm 2.4$ & tape & Nigeria
\end{tabular}

*ASD $=$ Ano-scrotal distance $* *$ AFD $=$ Ano-fourchette distance

Numerous studies have shown significant variations in AGD. It seems to be multifactorial and genetics, ethnicity, method of AGD measurement, birth weight, the age of the new born at the time of measurement are some of the factors $(1,5,6,15,18)$. There have been numerous studies demonstrating the ethnic and geographical variation of AGD. Sathyanarayana et al (19), who reported a longer AGD in Caucasian male infants in comparison with Asian or Native Americans. A study done in Greece and Spain, where the same measuring apparatus and the same anthropometrists obtained different AGD measurements in their study population, reflecting inter-country variations in AGD (5). However, there were not data for African countries. The tool used for measurement contributes to the observed differences in AGD measurements. A study in the United Kingdom, where a vernier caliper was also used for measurement, has demonstrated a very much lower mean AGD (19.8mm) compared to most of the other studies (6). In our study, the mean AGD at birth in male newborns, is similar to previously published studies where the flexible inelastic tape was used for their measurements $(14,20)$. In addition, our AGD measurements in males were in total agreement with the measurements reported by Papadopoulou et al $(27.1 \mathrm{~mm})$ in Greece, using a vernier caliper (6). In females, our mean AGD was also in keeping with those reported in previous studies $(5,14,21)$ but some differences were also observed $(6,13$, 15).

The body size and several other factors account for the longer AGD observed in males than females. Animal studies have shown that body size influence AGD and needs to be adjusted in studies concerning the effect of environmental pollutants on AGD (22, 23, 24). AGD of newborn infants also has a correlation with the birth weight, the length and the occipito-frontal circumference $(14,15)$. Therefore, when analyzing AGD data, it is important that adjustments are done for these parameters before comparing AGD data. Our data showed that sexual dimorphism in AGD persisted even after correcting for birth weight, length and occipitofrontal circumference (OFC) by calculating the adjusted AGD (AGD/ birthweight; AGD/ birth length; AGD/birth OFC, respectively).

There were some limitations in our present study. Maternal urinary levels of metabolites of endocrinedisrupting chemicals, which has the potential to affect the ano-genital anthropometric measurements were not assessed. The use of an inelastic flexible tape, which is not the ideal, rather than vernier caliper for the
AGD measurements was another limitation. However, a tape has the advantage of following the curves of the perineum, which the vernier caliper cannot do, and could be taken as an equally accurate measurement. Despite this limitation, the normative data reported in the present study are probably the most reliable data available for Nigeria.

\section{CONCLUSIONS}

Despite the limitations of our study, the results of this study provide a more reliable and comparable normative data that can be used as a standard with regard to AGD in Nigerian male and female newborns at birth.

\section{REFERENCES}

1. Kim TH, Lee HH, Kim JM, Yang YJ, Kim SY, Hong YP. The routine value of anogenital distance as an anthropometric measureme$\mathrm{nt}$ in newborns. Clinical and Experimental Obstetrics and Gynecology. 2014; 41(3):283-287.

2. Liu $\mathrm{C}, \mathrm{Xu} \mathrm{X}$, Huo $\mathrm{X}$. Anogenital distance and its application in environmental health research. Environmental Science and Pollution Research International. 2014; 21(18): 5457-5464. 
3. Wolf CJ, LeBlanc GA, Gray CE Jr. Interactive effects of vinclozin and testosterone propionate on pregnancy and sexual differentiation of the male and female SD rat. Toxicological Sciences. 2004; 78(1): 135-143.

4. Gray CE Jr, Wolf C, Lambright C, Mann P, Prince $\mathrm{M}$, Cooper RL et al. Administration of pote-ntially antiandrogenic pe-sticides (procymidone, linuron, iprodione, chlo-zolinate, p,p'DDE, and ketoconazole ) and toxic substances (dibutyl- and diethylhexyl phthalate, PCB 169, and ethane dimethane sulphonate) during sexual differentiation produces diverse profiles of reproductive malformations in male rat. Toxicology and Industrial Health. 1999; 15: 94118.

5. Papadopoulou E, Vafeiadi M, Agramunt S, Basagana X, Mathianaki K, Karakosta P et al. Anogenital distances in newborns and children from Spain and Greece: predictors, tracking and reliability. Pediatric and Perinatal Epidemiology. 2013; 27: 89-99.

6. Thankamony A, Ong KK, Dunger DB,Acerini CL, Hughes IA. Anogenital distance from birth to 2 years: a population study. Environ Health Perspective. 2009; 117: 1786-1790.

7. Arbuckle TE, Hanser R, Swan SH, Mao CS, Longnecker MP, Main KM et al. Meeting report: measuring endocrinesen-sitive endpoints within the first years of life. Environmental Health Perspectives. 2008; 116: 948-951.

8. Dean A, Sharpe RM. Anogenital distance or digit length ratio as measures of fetal androgen exposure: Relationship to male reproductive development and its disorders. Journal of Clinical Endocrinology and Metabolism. 2013; 98: 22302238.

9. Callegari C, Everett S, Ross M, Brasel JA. Anogenital ratio: measure of fetal virilization in premature and full-term newborn infants. Journal of Pediatrics. 1987; 111: 240-243.

10. Mendiola J, Roca M, MinguezAlaram L, Mira-Escolamo M, Lopez-Espin JJ, Barret ES et al. Anoge-nital distance is related to ovarian follicular number in young Spanish women: A cross-sectional study. Env-ironmental Health. 2012; 11: 90-97.

11. Romano-Riquer SP, Hernandez-Avila M, Gladen BC, Cupul-Uicab LA, Longnecker MP. Reliability and determinants of anogenital distance and penis dimensions in male newborns from Chipas, Mexico. Paediatric and Perinatal Epidemiology. 2007; 21(3): 219-228.

12. Salazar-Martinez E, RomanoRiquer P, Yanez-Marquez E, Longnecker MP, HernandezAvila M. Anogenital distance in human male and female newborns: A descriptive study. Environmental Health: $A$ Global Access Science Source. 2004; 3: 83-88.

13. Orish C, Didia B. Ano-genital distance in human male and female newborns: A look at a cross section of a Nigerian population. Int-ernet Journal of Biological An-thropology. 2008; 3(2): e1-4.

14. Ovidime OM, Olorunshola KV, Dikko AAU. Ano-genital distance of newborns and causes of variation in Zaria, Northern Nigeria. Asian Journal of Medical Sciences. 2011; 3(2): 74-78.

15. Özkan B, Konak B, Çayir A, Konak M. Anogenital distance in Turkish newborns. Journal of Clinical Pediatrics and Endocrinology. 2011; 3(3): 122-125.

16. Sathyanarayana $S$, Beard L, Zhou C, Grady R. Measurement and correlates of ano-genital distance in healthy newborn infants. International Journal of Andrology. 2010; 33(2): 317-323.

17. Welsh M, Saunders PTK, Fisken M, Scott HM, Hutchison GR, Smith LB et al. Identification in rats of a programming window for reproductive tract masculinezation, disruption of which leads to hypospadias and cryptorchidism. Journal of Clinical Investigation. 2008; 118(4): 1479-1490.

18. Bowman CJ, Barlow NJ, Turner KJ, Wallace DG, Foster PM. Effects of in utero exposure to finasteride on androgen-dependent reproductive development in the male rat. Toxicological Sciences. 2003; 74(2): 393-406

19. Oguz Kutlu A. Yenidogan kiz ve erkek bebekterde anogenital mesafe ölcümü kiz çocuklarda kolay bir klitoris ölcümü yöntemi ve klitoris büyüklügünü etkileyen faktörler. PP-A 11.12.13. www.cocukendokrindiyabet.or g/kongre 2007/ps 0103.htm.55.

20. Alaee E, Gharib MJ, Fouladinejad M. Penile length and anogenital distance in male newborns from different Iranian ethnincities in Golestan Province. Iran Red Crescent Medical Journal. 2014; 16(12): e16729.

21. Phillip M, De Boer C, Pilpel D, Karplus M, Sofer S. Clitoral and penile sizes of full-term newborns in two different ethnic groups. Journal of Pediatrics Endocrinology and Metabolism. 1996; 9(2): 175179.

22. Gallavan RH Jr, Holson JF, Stump DG, Knapp JF, Reynolds VL. Interpreting the toxicologic significance of alteration in anogenital distance: potential for confounding effects of progeny body weight. Reproductive Toxicology. 1999; 13: 383-390.

23. Swan SH, Main KM, Liu F, Stewart SL, Kruk RL, Calafat $\mathrm{AM}$ et al. Decrease in anogenital distance among male infants with prenatal phthalate exposure. Environmental Health Perspectives. 2005; 113: 1056-1061.

24. McEwen GH Jr, Renner G. Validity of anogenital distance as a marker of in utero phthalate exposure. Environmental Health Perspectives. 2006; 114: A19-A20. 